\title{
Impaired plasma phospholipids and relative amounts of essential polyunsaturated fatty acids in autistic patients from Saudi Arabia
}

\author{
Afaf K El-Ansary ${ }^{1,2,3,4^{*}}$, Abir G Ben Bacha ${ }^{1,2,3}$ and Layla Y Al- Ayadhi $i^{1,2,3,5}$
}

\begin{abstract}
Backgrounds: Autism is a developmental disorder characterized by social and emotional deficits, language impairments and stereotyped behaviors that manifest in early postnatal life. This study aims to compare the relative concentrations of essential fatty acids (Linoleic and $\alpha$ - linolenic), their long chain polyunsaturated fatty acids and phospholipids in plasma of autistic patients from Saudi Arabia with age-matching controls.

Methods: 25 autistic children aged 3-15 years and 16 healthy children as control group were included in this study. Relative concentration of essential fatty acids/long chain polyunsaturated fatty acids and omega-3/omega- 6 fatty acid series together with phosphatidylethanolamine, phosphatidylserine and phosphatidylcholine were measured in plasma of both groups.

Results: Remarkable alteration of essential fatty acids/long chain polyunsaturated fatty acids, omeg-3/omega-6 and significant lower levels of phospholipids were reported. Reciever Operating characteristics (ROC) analysis of the measured parameters revealed a satisfactory level of sensitivity and specificity.

Conclusion: Essential fatty acids/long chain polyunsaturated fatty acids and omeg-3/omega-6 ratios, phosphatidylethanolamine, phosphatidylserine and phosphatidylcholine could be used as potential biomarkers that point to specific mechanisms in the development of autism and may help tailor treatment or prevention strategies.
\end{abstract}

Keywords: Autism Polyunsaturated fatty acids, Essential fatty acids, Phospholipids, oxidative stress

\section{Introduction}

Autism is the most commonly studied of a spectrum of developmental disorders that are believed to be neurobiologically based but which, at this point, for lack of good biomarkers, are defined purely by behavior [1]. The number of cases has risen dramatically, and various hypotheses have been put forward to explain this phenomenon. Early estimates of the prevalence of this spectrum of disorders identified not less than 10 in 10,000 individuals as possessing some form of autism [2]. Autistic symptoms may also differ qualitatively from symptoms that characterize other disorders. Attention deficit, hyperactivity, and impulsivity are common in children with autism. Children with autism also have

\footnotetext{
* Correspondence: elansary@ksu.edu.sa

'Biochemistry Department, Science College, King Saud University, P.O Box 22452, Zip code 11495, Riyadh, Saudi Arabia

Full list of author information is available at the end of the article
}

the ability to hyperfocus on activities of interest to them, such as spending hours twirling a string or reading a book.

Essential fatty acids (EFAs) taken in diets mediate brain functions and structures during development and are involved in many brain related disorder like autism. Fatty acids are commonly classified as saturated, monounsaturated, and polyunsaturated (PUFA) fatty acids, depending on the chemical structure and the length of the chain that can vary from 12 to 26 carbon bonds. Two types of PUFAs are EFA: linoleic acid (LA: 18:2, n6) and $\alpha$-linolenic acid (ALA: 18:3, n-3). The brain cannot distinguish among longer chain fatty acids that have been synthesized in the brain, and those that have been obtained from diet and crossed the blood-brain barrier. Clearly, the blood-brain barrier is a key to the bioavailability of brain EFA and PUFAs. 
Among the significant components of cell membranes are the phospholipids that contain fatty acids. The brain phospholipids are exceptionally rich in PUFAs $[3,4]$ and in contrast to other bodily tissue, a unique feature of neurons is the smaller amounts of the precursors LA and ALA and the higher amounts of their metabolites: arachidonic acid (AA: 20:4, n-6) and docasahexaenoic acid (DHA: 22:6, n-3) [3-6]. The two major PUFAs in all vertebrates are AA and DHA [7] and account for $20 \%$ of the dry brain weight $[3,8]$. DHA is known to be involved in cell signaling and cell proliferation [9] and has an important structural role in the brain [10], whilst AA is crucial for brain growth. Eicosapentaenoic (EPA: 20:5, n-3) seemingly has no structural role, but it is considered vital for the regulation of brain function [10]. LysoPC is a preferred carrier form of DHA to the brain [11]. On the other hand, there is evidence that entry of PUFAs into brain microvessels involves phospholipase A2 (PLA2) and lipoprotein- induced methylation of phosphatidylethanolamine (PE) [12].

Abnormalities in the fatty acid compositions of phospholipids, the major constituents of cell membranes, have been implicated in several neurodevelopmental disorders that manifest with psychiatric symptoms. For example, in schizophrenia, changes of red blood cell (RBC) membrane phospholipids such as deficiencies in n-3 PUFAs have been reported [13-16]. Indeed, supplementing diets with fish oil was shown to correct these deficiencies and lead to improvements in the symptom scores of schizophrenic patients [17]. Similarly, defects of fatty acids and phospholipids have recently been reported in autism subjects, including not only reduced levels of n-3 PUFAs, but also increased levels of saturated fatty acids in the RBC membrane [18] or in plasma [3, ElAnsary A, Ben Bacha A, Al-Ayadhi L: Plasma fatty acids as diagnostic markers in autistic patients from Saudi Arabia, Submitted]. Further evidence from Bell et al. (2004) [19] suggested that decreased levels of AA, docosatetraenoic acid (DTA) and DHA in RBC membranes from autism subjects could be caused by increased activity of RBC type IV PLA2, suggesting that altered metabolism of phospholipids may occur in autism [19].

This information initiates our interest to evaluate the plasma levels of phosphatidyl choline (PC), phosphatidylserine (PS) and PE as three important members of brain phospholipids in autistic patients. Moreover the relative amounts of EFA and PUSFA will be measured in a trial to highlight the possibility of using these lipidrelated parameters as diagnostic markers.

\section{Materials and methods}

\section{Reagents and chemicals}

Chloroform and methanol used for extraction, ammonia $\left(\mathrm{NH}_{3}\right)$ and water methanol for the mobile phase were 99\% HPLC grade and obtained from Sigma-Aldrich (Taufkirchen, Germany). PC, PS and PE were obtained from Fluka, Sigma-Aldrich (Taufkirchen, Germany).

\section{Subjects and methods}

The study protocol followed the ethical guidelines of the most recent Declaration of Helsinki (Edinburgh, 2000). All subjects enrolled in the study ( 25 autistics and 16 controls) had written informed consent provided by their parents and assented to participate if developmentally able. They were enrolled through the ART Center (Autism Research \& Treatment Center) clinic. The ART Center clinic sample population consisted of children diagnosed on the autism spectrum (ASD). The diagnosis of ASD was confirmed in all subjects using the Autism Diagnostic Interview-Revised (ADI-R) and the Autism Diagnostic Observation Schedule (ADOS) and 3DI (Developmental, dimensional diagnostic interview). The ages of all autistic children participate between the ages of 4 and 12 years old. All were simplex cases. All are negative for fragile $\mathrm{x}$ gene study. The control group recruited from well baby clinic at king Khaled university hospital with mean age 4-11 years old. Subjects were excluded from the investigation if they had dysmorphic features, or diagnosis of Fragile X or other serious neurological (e.g., seizures), psychiatric (e.g., bipolar disorder) or known medical conditions. All participants were screened via parental interview for current and past physical illness. Children with known endocrine, cardiovascular, pulmonary, liver, kidney or other medical disease were excluded from the study.

\section{Samples collection}

Blood samples were collected in the morning following at least 10 hour period of fasting. Plasma was collected using standard clinical practices and stored at $-80^{\circ} \mathrm{C}$ until thawed for analysis.

\section{Lipid extraction and chromatography}

- Measurement of EFA and PUSFA: Plasma $(200 \mu \mathrm{l})$ lipids were extracted in the presence of internal standards and FA methylated using $3 \mathrm{~N}$ methanolic HCL in sealed vials under nitrogen and incubated at $100 \mathrm{C}$ for $45 \mathrm{~min}$. The methyl esters of free fatty acids were extracted with hexane, and the fatty acid composition of the extract was analyzed on a gas chromatograph (Helwlett-Packard 5890 series II plus, HP analytical Direct, Wilmington, DE), equipped with a flame ionization 
detector and a $30 \mathrm{~m} \times 0.25 \mathrm{~mm} \times 0.25 \mu \mathrm{m}$ capillary column( Omegawax 250\# 2-4136, Supelco). The helium gas flow rate was $1.2 \mathrm{ml} / \mathrm{min}$, with a split/flow ratio of 50:1. Oven temperature was held at $205^{\circ} \mathrm{C}$. The injector and detector temperatures were 260 and $262^{\circ} \mathrm{C}$, respectively. Two internal standards, C15:0 and C23:0, were added during analysis. Fatty acids were identified via comparison of retention times with authentic standards [20].

- Phospholipids Measurement: Phospholipid separation was performed on a Kaneur Maxi Star HPLC system with four solvent lines, a degasser SEDEX 55 evaporating light detector (SEDEX 55 Lichtstreu detector, S.E.D. E.E., France) which was coupled with Apex M625 software (Autochrom, USA). As the nebulizing gaz, $\mathrm{N}_{2}$ was used at a flow rate of $41 / \mathrm{min}$, and a nebulizing temperature of $40^{\circ} \mathrm{C}$. The gain was set at 8 and 2.0 bar $\mathrm{N}_{2}$.

A $125 \times 4.0 \mathrm{~mm} \mathrm{Si-60} \mathrm{column} \mathrm{with} 5 \mu \mathrm{m}$ particle diameter (Lichrosher) was used. The elution program was a linear gradient with 80:19.5:0.5 (V/V) chloroform: methanol: water: ammonia $\left(\mathrm{NH}_{3}\right)$ at $22 \mathrm{~min}$ and the column was allowed to equilibrate until the next injection at $27 \mathrm{~min}$. The injection volume was $50 \mu \mathrm{l}$. A liquid phase extraction procedure adapted from the method described by Bligh and Dyer (1959) was used to extract the serum samples.

Briefly, $50 \mu \mathrm{l}$ of sample was diluted with $750 \mu \mathrm{l}$ deionized water and mixed well. Then $2 \mathrm{ml}$ of methanol and $1 \mathrm{ml}$ of chloroform were added to the sample and mixed well. Then the mixture was homogenized (Rotary mixture 34526, Snijders) for $15 \mathrm{~min}$. The mixture was centrifuged for 5 min by $4000 \mathrm{rpm}$.

\section{Statistical analysis}

An SPSS computer program was used. Results were expressed as mean \pm S.D. and all statistical comparisons were made by means of independent $\mathrm{t}$-Test with $\mathrm{P} \leq$ 0.005 was considered significant. Reciever Operating Characteristics analysis (ROC) was performed. Area under the curve, cutoff values together with degree of specificity and sensitivity were calculated. ROC curves are constructed by plotting the false positive rate (i.e. 100-specificity) against the true positive rate (i.e. sensitivity). These have been widely accepted as standard tools for evaluating the performance of diagnostic tests. The AUC is an overall summary of diagnostic accuracy, incorporating both components of accuracy, i.e., sensitivity and specificity, into a single measure. The AUC has been widely used as a quantitative index of the performance of a biomarker in a variety of applied fields; it is a simple and convenient overall measure of diagnostic test $[21,22]$.

\section{Results and Discussion}

EFAs and their long chain PUFAs are of critical importance in fetal growth and development [23-26]. These fatty acids are the precursors of eicosanoids and are essential constituents of the membrane lipids that maintain cellular and organelle integrity and important intracellular mediators of gene expression [27-29].

Table 1 shows that autistic patients of Saudi Arabia recorded a remarkable higher LA/AA and ALA/DHA ratios compared to age-matching controls. It appears that the same enzymes catalyze the conversion of both omega- 6 and omega-3 fatty acid precursors into PUFAs. As reported by Pawlosky et al (2001) [30], the first step of the conversion process, ALA to EPA, is the rate-limiting step, with only $0.2 \%$ of ALA converted to EPA. The enzyme responsible for this conversion also converts docosapentaenoic acid (DPA) to the final product DHA but at a much higher rate (37\%), suggesting that the enzyme has a low affinity for ALA. These enzymes are regulated by a negative feedback loop, suggesting that the dietary balance of different fatty acids is important [31]. The desaturation enzymes are only fully induced when levels of PUFAs are low, whereas if there is an adequate level of fatty acids, these desaturases are suppressed. Based on these information, we can suggest that a poorer ability to convert 18-carbon FA (LA and ALA) to their longer and more highly unsaturated derivatives could be considered in autistic patients of Saudi Arabia. This explanation could be supported through considering the previous work of Herault et al. (1993) [32] who detected a site linked to autism located on chromosome 11q22-23, in the viciny of the gene for delta- 6 desaturase, which is the enzyme first involved in the production of PUFA-long chain derivatives of both $(n-3)$ and (n-6) series [33]. The obtained results could find a support by the previous work of Richardson and Ross (2000) [16] in which an impairment of PUFAs metabolism has also been postulated to occur in children suffering from attention-deficit hyperactivity

Table 1 Mean \pm S.D of LA/AA, ALA/DHA, AA/DHA, EPA/ DHA and EPA/AA ratios in plasma of autistic patients ( $N$ $=25$ ) compared to age- matching controls $(N=16)$.

\begin{tabular}{|c|c|c|c|c|c|}
\hline Parameters & Groups & Min. & Max. & Mean \pm S.D & $P$ value \\
\hline \multirow[t]{2}{*}{ LA/AA } & Control & 0.48 & 1.02 & $0.62 \pm 0.16$ & 0.034 \\
\hline & Autistic & 0.41 & 3.31 & $1.08 \pm 0.90$ & \\
\hline \multirow[t]{2}{*}{ ALA/DHA } & Control & 0.17 & 1.26 & $0.59 \pm 0.36$ & 0.004 \\
\hline & Autistic & 0.43 & 1.18 & $0.84 \pm 0.19$ & \\
\hline \multirow[t]{2}{*}{ AA/DHA } & Control & 0.47 & 0.99 & $0.81 \pm 0.17$ & 0.000 \\
\hline & Autistic & 0.19 & 0.61 & $0.33 \pm 0.14$ & \\
\hline \multirow[t]{2}{*}{ EPA/DHA } & Control & 0.17 & 1.44 & $0.56 \pm 0.39$ & 0.576 \\
\hline & Autistic & 0.42 & 1.07 & $0.61 \pm 0.19$ & \\
\hline \multirow[t]{2}{*}{ EPA/AA } & Control & 0.24 & 1.46 & $0.66 \pm 0.37$ & 0.000 \\
\hline & Autistic & 1.01 & 3.49 & $0.96 \pm 0.20$ & \\
\hline
\end{tabular}

Fatty acids are expressed in $\mathrm{mmol} / \mathrm{L}$ plasma. Significant level at $\mathrm{p}<0.01$ 
Table 2 Mean \pm S.D of plasma levels of PC, PS and PC (expressed in mmol/L plasma) in autistic patients compared to age- matching controls.

\begin{tabular}{lllllll}
\hline Parameter & Group & N & Minimum & Maximum & Mean \pm S.D & P value \\
\hline PE & Control & 16 & 0.022 & 0.059 & $0.043 \pm 0.010$ \\
\cline { 2 - 6 } & Autistic & 25 & 0.021 & 0.063 & $0.032 \pm 0.009$ \\
\hline PS & Control & 16 & 0.065 & 0.0992 & $0.081 \pm 0.009$ \\
\cline { 2 - 6 } & Autistic & 25 & 0.034 & 0.067 & $0.051 \pm 0.009$ & $1.711 \pm 0.185$ \\
\hline PC & Control & 16 & 1.369 & 1.979 & $1.313 \pm 0.333$ \\
\cline { 2 - 6 } & Autistic & 25 & 0.862 & 1.989 & 0.000 \\
\hline
\end{tabular}

Significant level at $p<0.005$

disorder (ADHD). This term is used to describe children, particularly boys, who are inattentive, impulsive and hyperactive [34]. Moreover, Mitchell et al. (1987) [35] and Stevens et al (1995) [36] showed that the proportions of DHA and AA were significantly lower in the plasma of ADHD children. They recorded that approximately $40 \%$ of subjects with ADHD had a greater frequency of symptoms indicative of EFAs deficiency (increased thirst, frequent urination, high fluid

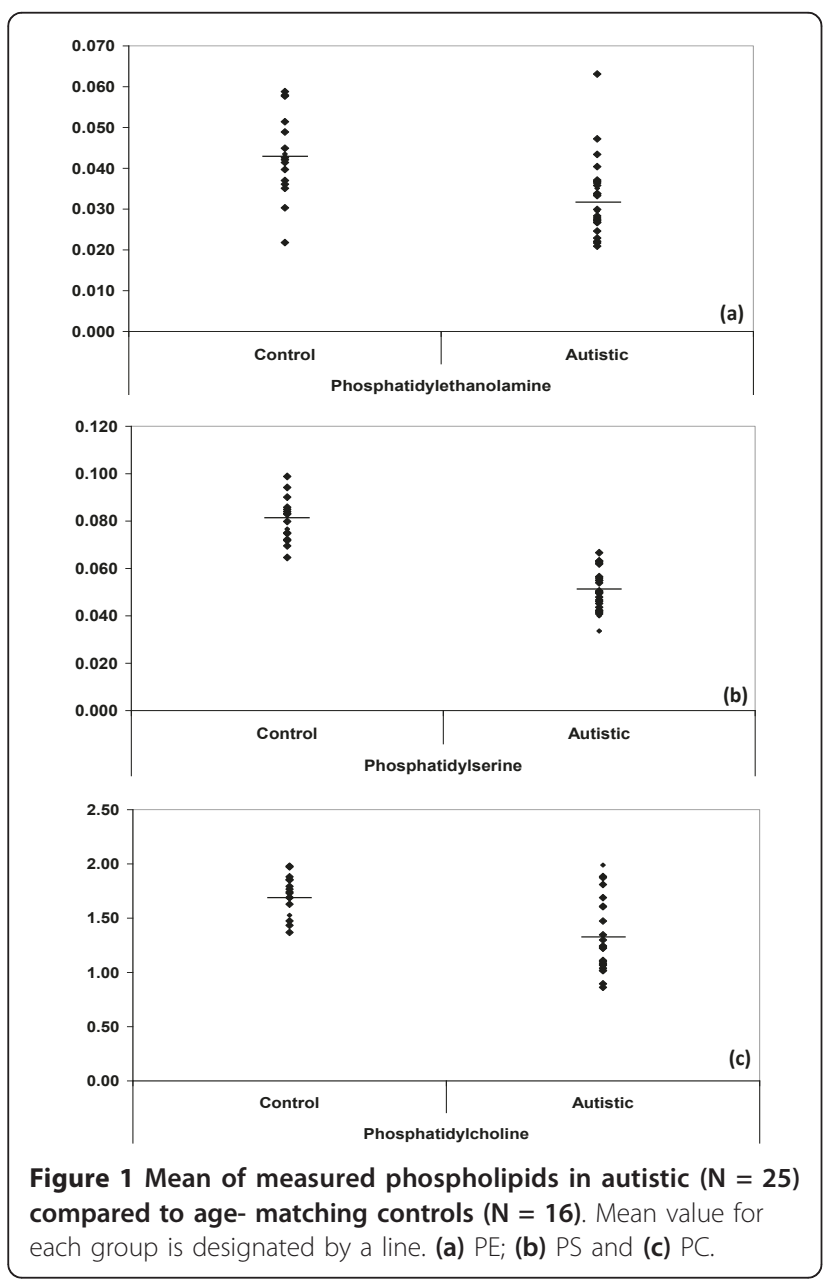

consumption, dry hair), compared to age- matching controls. The decreased levels of AA and DHA reported in the present study may be caused by increased activity of phospholipase A2 [19].

Autism exhibits a marked gender bias with approximately four times more males diagnosed than females [37]. Although prepubertal boys and girls have similar testosterone levels (3.9 vs. $4.7 \mathrm{ng} / \mathrm{dL}$ ) [38], prepubertal girls have 8-fold higher levels of estrogen than prepubertal boys ( 0.6 vs. $0.08 \mathrm{pg} / \mathrm{mL}$ [39]. Estrogen is neuroprotective against glutamate-induced neurotoxicity $[40,41]$. Further evidence regarding the protective characteristics of circulating estrogen levels comes from the work of Djouadi and colleagues (1998) [42]. Extier et al. (2009) [43] strongly suggest that male testosterone down- regulates while female estradiol up-regulates the synthesis of long chain n-3 PUFAs from ALA. This information could be helpful to suggest that deficiency of AA and DHA in Saudi autistic patients is greatly contributed in the etiology of the disorder.

Table 1 also demonstrates a much lower AA/DHA in autistic patients of Saudi Arabia compared to agematched control. This could be attributed to a combination of factors including altered enzyme activity affecting conversion of LA and ALA as precursor fatty acids and/ or excessive utilization of these metabolites. The

Table 3 ROC analysis of LA/AA, ALA/DHA, AA/DHA, EPA/ DHA and EPA/AA ratios and PE, PS and PC in autistic groups ( $\mathrm{N}=25)$.

\begin{tabular}{lcccc}
\hline Parameter & $\begin{array}{c}\text { Area under the } \\
\text { curve }\end{array}$ & $\begin{array}{c}\text { Cutoff } \\
\text { value }\end{array}$ & $\begin{array}{c}\text { Sensitivity } \\
\%\end{array}$ & $\begin{array}{c}\text { Specificity } \\
\%\end{array}$ \\
\hline LA/AA & 0.592 & 0.69 & $60.0 \%$ & $84.6 \%$ \\
\hline ALA/DHA & 0.713 & 0.57 & $90.9 \%$ & $61.5 \%$ \\
\hline AA/DHA & 0.977 & 0.66 & $100.0 \%$ & $84.6 \%$ \\
\hline EPA/DHA & 0.658 & 0.39 & $100.0 \%$ & $46.2 \%$ \\
\hline EPA/AA & 0.937 & 1.07 & $93.8 \%$ & $84.6 \%$ \\
\hline PE & 0.806 & 0.037 & $80.0 \%$ & $75.0 \%$ \\
\hline PS & 0.998 & 0.068 & $100.0 \%$ & $93.7 \%$ \\
\hline PC & 0.825 & 1.619 & $80.0 \%$ & $75.0 \%$ \\
\hline
\end{tabular}


recorded lower AA/DHA reported in the present study in autistic patient could be also explained on the basis that within body tissues, DHA status fluctuates quite readily with dietary changes while AA concentrations remain relatively stable and that there is little difference in AA content amongst individuals [44]. Therefore, the occurrence of a subnormal AA concentration in Saudi autistics [El-Ansary A, Ben Bacha A, Al-Ayadhi L: Plasma fatty acids as diagnostic markers in autistic patients from Saudi Arabia, Submitted.] may be of particular importance than DHA and could be physiologically relevant to abnormal brain function. Table 1 also showed that autistic patients had a significantly higher EPA/AA ratio which confirmed that they have much higher n-3/n-6 fatty acids. This is in good agreement with the previous reports of Wiest et al. (2009) [45] that individuals with autism had higher concentrations of long-chain n-3 fatty acids in both PE and PC, and tended to have lower concentrations of long-chain n- 6 fatty acids. They attributed this elevated ratio to the fact that plasma lipid profiles are known to be affected by increased consumption of n-3-rich food e.g fish, raising EPA and DHA.

Consistent with the increased oxidative stress biomarkers, Saudi children with autism were found to have increased body burdens of lipid peroxides [46]. A second line of evidence that oxidative stress may play a role in autism in Saudi population is suggested by a

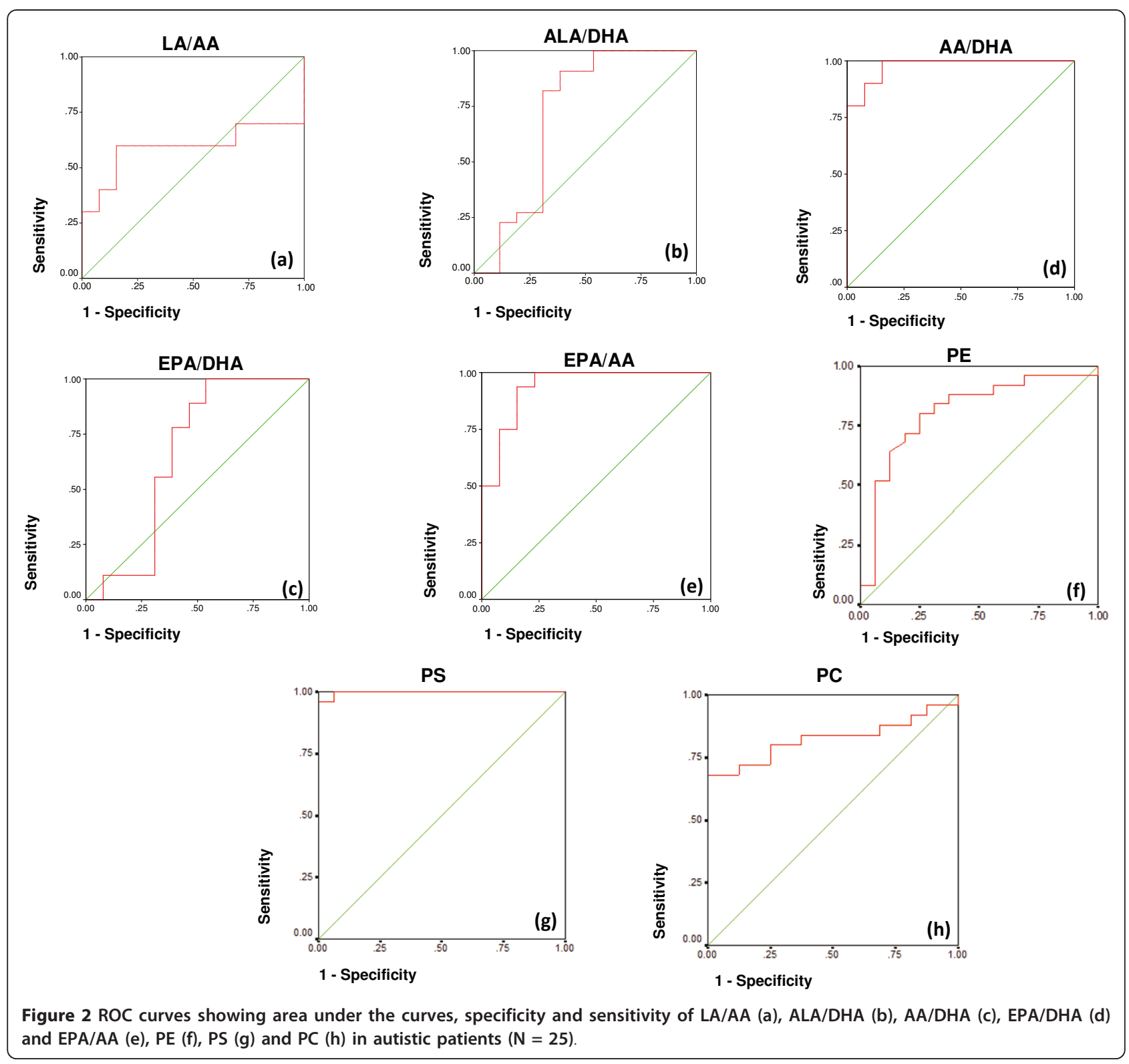


reduced endogenous antioxidant capacity. Specifically, altered glutathione peroxidase (GPX), superoxide dismutase (SOD), catalase activities as well as total GSH and vitamin E [46]. Lower AA concentration recorded in the present study could be easily related to the oxidative stress as an accepted mechanism in the etiology of autism. This suggestion could be supported through considering the previous work of Ming et al. (2005) [47] in which they recorded urinary excretion of 8-isoprostane (8-iso-PGF2a) a class of autoxidation products generated from AA acid by a free radical initiated process, in children with autism compared to age-matched controls.

In eukaryotic cells, phospholipids are the predominant membrane lipids and are, from a topographic point of view, asymmetrically distributed across the bilayer $[48,49]$. PC, PE, PS, are the major phospholipids [50]. In most eukaryotic membranes, PC and PE represent together around $60-85 \%$ of the phospholipids fraction, while for the other phospholipids small but significant differences can be found depending of the cell membrane and even animal species [51,52]. Phospholipids play multiple roles. They constitute a permeability barrier, modulate the functional properties of membraneassociated activities, provide a matrix for the assembly and function of a wide variety of catalytic processes, and act as donors during the synthesis of macromolecules. The wide range of processes in which phospholipids are specifically involved explains the need for diversity in phospholipid structures and fatty acid composition [53].

Table 2 and Figure 1 demonstrated that PE, PS and $\mathrm{PC}$ were significantly lower in autistic patients compared to healthy control. This could be easily correlated to certain autistic features specially those related to oxidative stress and inflammatory responses as two mechanisms have been shown to play a critical role in the pathophysiology of autism. This could find a

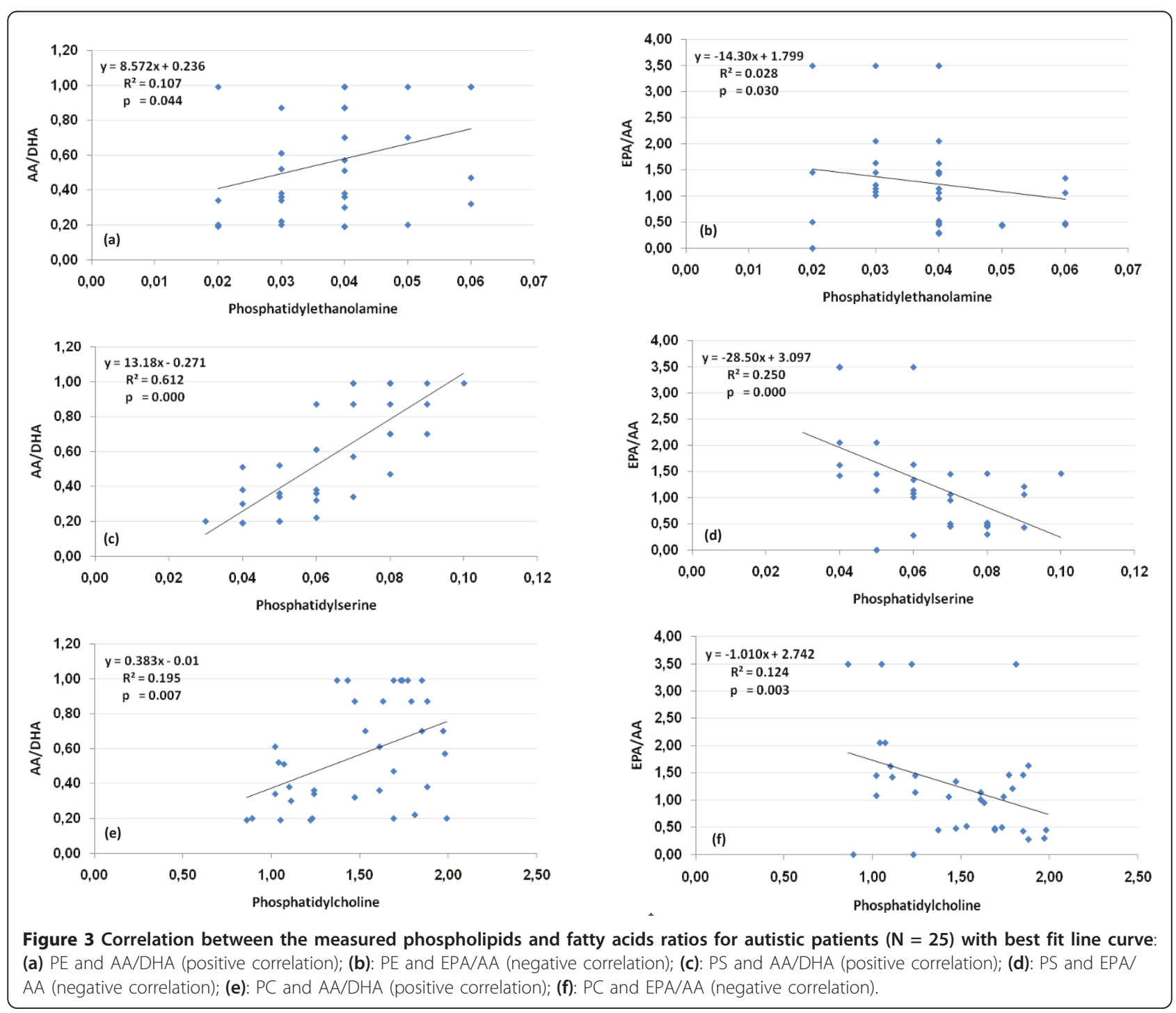


support through considering the reports of Pandey et al. (2009) [54] that Omega-6 phospholipids, e.g. PC have been shown to have anti-inflammatory properties through inhibiting tumor necrosis factor (TNF- $\alpha$ ) and $\mathrm{H}_{2} \mathrm{O}_{2}$ activated mitogen-activated protein kinase (MAPK) in neuronal cell line SH-SY5Y cells and prevents the phosphorylation and activation of nuclear factor-kappa B. The lower concentration of PC reported in the present study could explain the previously proved $\mathrm{H}_{2} \mathrm{O}_{2}$ intoxication in plasma samples collected from the same autistic patients [46] and explain the increase of pro-inflammatory cytokines in autistic patients [55].

The obtained lower PS presented in Table 2 and Figure 1 in plasma of autistic patients compared to age- matching controls could be easily correlated to the over expression of superoxide dismutase (SOD) as a phenotype previously reported by Al-Gadani et al. (2009) [46] in autistic patients from Saudi Arabia. Glozman et al. (2000) [56] proved that $\mathrm{Cu} / \mathrm{Zn}$-SOD gene are compatible with DHA and PS deficiency in the fetal, but not the adult brain.

It is well documented that phospholipids enriched in unsaturated fatty acids (PE, PS and PC) are crucial to the normal neurological function of the brain. Neurodegeneration has been shown to be associated with abnormal phospholipids metabolism in the brain [57]. Erythrocyte membrane phospholipid composition has been shown to correlate to brain phospholipid composition [58] and may be a useful marker for neurological disease $[59,60]$.

ROC analysis presented in table 3 together with figure 2 demonstrate that AA/DHA, EPA/AA and the three measured phospholipids (PE, PS and PC) showed a satisfactory specificity and sensitivity and they could be uses as biomarkers for the early diagnosis of autism in Saudi populations.

Figure 3 demonstrate the Pearson correlation test between fatty acid ratios and phospholipids concentrations. PE, PS and PC are correlated negatively with EPA/AA and positively with the AA/DHA which highlight the relationship between AA deficiency and the etiopathology of autism. This support the previously mentioned phenomena that subnormal concentration of AA is more related to autism than DHA and EPA as two PUSFAs greatly affected by diet.

In conclusion, since erythrocyte phospholipid composition is impacted by dietary habits, the therapeutic early administration of omega- 6 phospholipids, such as PC, would be expected to increase the concentration of these lipids in both the plasma and brain and promote neuronal anti-inflammatory events.

\section{Abbreviations}

PUFA: polyunsaturated fatty acid; EFA: Essential fatty acids; LA: linoleic acid; ALA: a-linolenic acid; AA: Arachidonic acid; DHA: Docasahexaneoic acid;
EPA: Eicosapentaenoic; PC: phosphatidylcholine; PE: phosphatidylethanolamine; PS: phosphatidylserine; ADHD: attention-deficit hyperactivity disorder.

\section{Acknowledgements}

The authors would like to thank Shaik AL-Amodi Autism Research Chair and the parents of autistic children, without whom this work was not possible. This work was supported by King Abdul Aziz City for Science and Technology (KACST).

\section{Author details}

'Biochemistry Department, Science College, King Saud University, P.O Box 22452, Zip code 11495, Riyadh, Saudi Arabia. ${ }^{2}$ Autism Research and Treatment Center, King Saud University, P O Box 2925 Riyadh 11461 Saudi Arabia. ${ }^{3}$ Shaik AL-Amodi Autism Research Chair, King Saud University, P O Box 2925 Riyadh 11461 Saudi Arabia. ${ }^{4}$ Medicinal Chemistry Department, National Research Centre, P O Box 12622, Dokki, Cairo, Egypt. ${ }^{5}$ Department of Physiology, Faculty of Medicine, King Saud University, P O Box 2925 Riyadh 11461 Saudi Arabia.

\section{Authors' contributions}

AE: Designed the study and drafted the manuscript.

$A B B$ : Helped to draft the manuscript and performed the statistical analysis. LA: Provided samples and participated in the design of the study.

All authors read and approved the final manuscript.

\section{Competing interests}

The authors declare that they have no competing interests.

Received: 3 March 2011 Accepted: 22 April 2011

Published: 22 April 2011

\section{References}

1. Lord CE: Autism: From Research to Practice. American Psychologist 2010, 6:815-826.

2. Matson $J \mathrm{~L}$, Kozlowski AM: The increasing prevalence of autism spectrum disorders. Research in Autism Spectrum Disorders 2011, 5:418-425.

3. Vancassel S, Durand G, Barthelemy C, Lejeune B, Martineau J, Guilloteau D, Andrès C, Chalon S: Plasma fatty acid levels in autistic children. Prostaglandins Leukot Essent Fatty Acids 2001, 65:1-7.

4. Horrobin DF: The membrane phospholipid hypothesis as a biochemical basis for the neurodevelopmental concept of schizophrenia. Schizophr Res 1998, 30:193-208

5. Bourre J: Fatty acids, cognition, behavior, brain development, and mood diseases.Edited by: Chow C. Fatty Acids in Foods and their Health Implications, CRC, Hoboken; 2007:935-954.

6. Conklin S, Reddy R, Muldoon M, Yao J: Fatty acids and psychiatric disorders.Edited by: Chow C. Fatty Acids in Foods and their Health Implications, CRC, Hoboken; 2007:1229-1256.

7. Alessandri J, Guesnet P, Vancassel S, Astorg P, Denis I, Langelier B, Aïd S, Poumès-Ballihaut C, Champeil-Potokar G, Lavialle M: Polyunsaturated fatty acids in the central nervous system: evolution of concepts and nutritional implications throughout life. Reprod Nutr Dev 2004, 44:509-538.

8. Meguid N, Atta H, Gouda A, Khalil R: Role of polyunsaturated fatty acids in the management of Egyptian children with autism. Clin Biochem 2008, 41:1044-1048.

9. Salem N, Litman B, Kim H, Gawrisch K: Mechanisms of action of docosahexaenoic acid in the nervous system. Lipids 2001, 36:945-959.

10. Richardson A: Fatty acids in dyslexia, dyspraxia, ADHD and the autistic spectrum. Nutrition 2001, 3:18-24.

11. Lagarde M, Bernoud N, Brossard N, Lemaitre-Delaunay D, Thies F, Croset M, Lecerf J: Lysophosphatidylcholine as a preferred carrier form of docosahexaenoic acid to the brain. J Mol Neurosci 2001, 16:201-204.

12. Magret V, Elkhalil L, Nazih-Sanderson F, Martin F, Bourre JM, Fruchart JC, Delbart C: Entry of polyunsaturated fatty acids into the brain: evidence that highdensity lipoprotein-induced methylation of phosphatidylthanolamine and phospholipase A2 are involved. Biochem J 1996, 316:805-811.

13. Peet M, Laugharne JD, Mellor J, Ramchand CN: Essential fatty acid deficiency in erythrocyte membranes from chronic schizophrenic 
patients and the clinical effects of dietary supplementation. Prostaglandins Leukot Essent Fatty Acids; 1996:55:71-75.

14. Richardson AJ, Calvin CM, Clisby C, Schoenheimer DR, Montgomery P, Hall JA, Hebb G, Westwood E, Talcott JB, Stein JF: Fatty acid deficiency signs predict the severity of reading and related difficulties in dyslexic children. Prostaglandins Leukot Essent Fatty Acids 2000, 63:69-74

15. Richardson AJ, Easton T, Puri BK: Red cell and plasma fattyacid changes accompanying symptom remission in a patient with schizophrenia treated with eicosapentaenoic acid. Eur Neuropsychopharmacol 2000, 10:189-193.

16. Richardson AJ, Ross MA: Fatty acid metabolism in neurodevelopmental disorder: a new perspective on associations between attention-deficit/ hyperactivity disorder dyslexia, dyspraxia and the autistic spectrum. Prostaglandins Leukot Essent Fatty Acids 2000, 63:1-9.

17. Arvindakshan M, Ghate M, Ranjekar PK, Evans DR, Mahadik SP: Supplementation with a combination of omega-3 fatty acids and antioxidants (vitamins $E$ and C) improves the outcome of schizophrenia. Schizophrenia Res 2003, 62:195-204.

18. Bell JG, Sargent JR, Tocher DR, Dick JR: Red blood cell fatty acid compositions in a patient with autistic spectrum disorder: a characteristic abnormality in neurodevelopmental disorders? Prostaglandins Leukot Essent Fatty Acids 2000, 63:21-25.

19. Bell JG, MacKinlay EE, Dick JR, MacDonald DJ, Boyle RM, Glen AC: Essential fatty acids and phospholipase $\mathrm{A} 2$ in autistic spectrum disorders. Prostaglandins Leukot Essent Fatty Acids 2004, 71:201-204.

20. Folch J, Lees M, Stanley GHS: A simple method for the isolation and purification of lipids from animal tissues. J Biol Chem 1957, 226:497-509.

21. Pepe MS: The statistical evaluation of medical tests for classification and prediction. Woxford Statistical Science Series; 200328.

22. Zhou XH, Obuchowski N, McClish D: Statistical Methods in Diagnostic Medicine. Wiley, New York; 2002.

23. Duttaroy AK: Transport mechanisms for long-chain polyunsaturated fatty acids in the human placenta. Am J Clin Nutr 2000, 71:315S-22S.

24. Innis SM: Perinatal biochemistry and physiology of long-chain polyunsaturated fatty acids. J Pediatr 2003, 143:S1-8.

25. Innis SM: Essential fatty acid transfer and fetal development. Placenta 2005, 26:570-5

26. Innis SM: Fatty acids and early human development. Early Hum Dev 2007, 83(12):761-6

27. Schmitz $G$, Ecker J: The opposing effects of $n-3$ and $n-6$ fatty acids. Prog Lipid Res 2008, 47:147-155.

28. Uauy $R$, Hoffman DR, Peirano P, Birch DG, Birch EE: Essential fatty acids in visual and brain development. Lipids 2001, 36:885-895.

29. Jump DB: Fatty acid regulation of gene transcription. Crit Rev Clin Lab Sci 2004, 41:41-78

30. Pawlosky RJ, Hibbeln JR, Novotny JA, Salem N Jr: Physiological compartmental analysis of alpha-linolenic acid metabolism in adult humans. J Lipid Res 2001, 42:1257-1265.

31. Nakamura MT, Nara TY: Structure, function, and dietary regulation of Delta6, Delta5, and Delta9 desaturases. Annu Rev Nutr 2004, 24:345-376.

32. Herault J, Perrot A, Barthelemy C, Buchler M, Cherpi C, Leboyer M, Sauvage D, Lelord G, Mallet J, Müh JP: Possible association of c-HarveyRas-1 (HRAS-I) marker with autism. Psychiatry Res 1993, 46:216-267.

33. Horrobin DF, Bennett CN: New gene targets related toschizophrenia and other psychiatric disorders: enzymes, bindingproteins and transport proteins involved in phospholipid and fatty acid metabolism. Prostaglandins Leukot Essent Fatty Acids 1999, 60:141-167.

34. American Psychriatric Association: Diagnostic and Statistical Manual for Mental Disorders. DSM IV. Washington, DC: American Psychiatric Press; 4 1994.

35. Mitchell EA, Aman MG, Turbott SH, Manku M: Clinical characteristics and serum essential fatty acid levels in hyperactive children. Clin Pedriatr 1987, 26:406-411.

36. Stevens $L$, Zentall SS, Deck JL, Abate ML, Watkins BA, Lipp SR, Burgess JR: Essential fatty acid metabolism in boys with attention-deficit hyperactivity disorder. Am J Clin Nutr 1995, 62:761-768.

37. Fombonne E: Epidemiology of autistic disorder and other pervasive developmental disorders. J Clin Psychiatry 2005, 66(Suppl 10):3-8.

38. Horlick MB, Rosenbaum M, Nicolson M, Levine LS, Fedun B, Wang J, Pierson RN Jr, Leibel RL: Effect of puberty on the relationship between circulating leptin and body composition. J Clin Endocrinol Metab 2000, 85:2509-2518.

39. Klein KO, Baron J, Colli MJ, McDonnell DP, Cutler GB Jr: Estrogen levels in childhood determined by an ultrasensitive recombinant cell bioassay. $J$ Clin Invest 1994, 94:2475-2480.

40. McClean J, Nunez JL: 17alpha-Estradiol is neuroprotective in male and female rats in a model of early brain injury. Exp Neurol 2008, 210:41-50.

41. Mendelowitsch A, Ritz MF, Ros J, Langemann H, Gratzl O: 17beta-Estradiol reduces cortical lesion size in the glutamate excitotoxicity model by enhancing extracellular lactate: a new neuroprotective pathway. Brain Res 2001, 901:230-236.

42. Djouadi F, Weinheimer CJ, Saffitz JE, Pitchford C, Bastin J, Gonzalez FJ, Kelly DP: A gender-related defect in lipid metabolism and glucose homeostasis in peroxisome proliferator-activated receptor alphadeficient mice. J Clin Invest 1998, 102:1083-1091.

43. Extier A, Perruchot MH, Baudry C, Guesnet P, Lavialle M, Alessandri JM: Differential effects of steroids on the synthesis of polyunsaturated fatty acids by human neuroblastoma cells. Neurochemistry International 2009, 55:295-301.

44. Muskiet FAJ, Fokkema MR, Schaafsma A, Boersma ER, Crawford MA: Is docosahexaenoic acid (DHA) essential? Lessons from DHA status, regulation, our ancient diet, epidemiology and randomized controlled trials. J Nutr 2004, 134:183-186.

45. Wiest MM, German JB, Harvey DJ, Watkins SM, Hertz-Picciotto I: Plasma fatty acid profiles in autism: a case-control study. Prostaglandins, Leukot Essent Fatty Acids 2009, 80:221-227.

46. Al-Gadani Y, El-Ansary A, Attas O, Al-Ayadhi L: Oxidative stress and antioxidant status in Saudi autistic children. Clin Biochem 2009, 42:1032-1040.

47. Ming X, Stein TP, Brimacombe M, Johnson WG, Lambert GH, Wagne GC: Increased excretion of a lipid peroxidation biomarker in autism. Prostaglandins, Leukotrienes and Essential Fatty Acids 2005, 37:379-384.

48. Ikeda M, Kihara A, Igarashi Y: Lipid asymmetry of the eukaryotic plasma membrana: functions and related enzymes. Biol Pharm Bull 2006, 29:1542-1546.

49. Lenoir G, Williamson P, Holthuis JCM: On the origin of lipid asymmetry: the flip side of ion transport. Curr Opin Chem Biol 2007, 11:654-661.

50. Vance DE, Vance JE: Biochemistry of Lipids, Lipoproteins and Membranes. Elsevier Science BV, Amsterdam, The Netherlands; 1996, 1-553.

51. Van Meer G, Voelker DR, Feigenson GW: Membrane lipids: where they are and how they behave. Nature Rev Mol Cell Biol 2008, 9:112-124.

52. Mitchell TW, Buffenstein R, Hulbert AJ: Membrane phospholipid composition may contribute to exceptional longevity of the naked mole-rat (Heterocephalus glaber): a comparative study using shotgun. lipidomics Exp Gerontol 2007, 42:1053-1062.

53. Dowhan W: Molecular basis for membrane phospholipid diversity: why are there so many lipids? Annu Rev Biochem 1997, 66:199-232.

54. Pandey NR, Sultan K, Twomey E, Sparks DL: Phospholipids block nuclear factor-kappa B and tau phosphorylation and inhibit amyloid-beta secretion in human neuroblastoma cells. Neuroscience 2009, 164:1744-1753.

55. Ashwood P, Krakowiak P, Hertz-Picciotto I, Hansen R, Pessah I, Van de Water J: Elevated plasma cytokines in autism spectrum disorders provide evidence of immune dysfunction and are associated with impaired behavioral outcome. Brain Behav Immun 2011, 25:40-45.

56. Glozman S, Cerruti-Harris C, Groner Y, Yavin E: Docosahexaenoic acid-dec cient phosphatidyl serine and high $\mathrm{K}$-tocopherol in a fetal mouse brain over-expressing Cu/Zn-superoxide dismutase. Bioch Biophy Acta 2000, 1487:135-144.

57. Bazan NG: Neuroprotectin D1 (NPD1): a DHA-derived mediator that protects brain and retina against cell injury-induced oxidative stress. Brain Pathol 2005, 15:159-166.

58. Connor J, Gillum K, Schroit AJ: Maintenance of lipid asymmetry in red blood cells and ghosts: effect of divalent cations and serum albumin on the transbilayer distribution of phosphatidylserine. Biochim Biophys Acta 1990, 1025:82-86.

59. Fenton WS, Hibbeln J, Knable M: Essential fatty acids, lipid membrane abnormalities, and the diagnosis and treatment of schizophrenia. Biological Psychiatry 2000, 47:8-21. 
60. Sumiyoshi T, Matsui M, Itoh H, Higuchi Y, Arai H, Takamiya C, Kurachi M: Essential polyunsaturated fatty acids and social cognition in schizophrenia. Psychiatry Res 2008, 157:87-93.

doi:10.1186/1476-511X-10-63

Cite this article as: El-Ansary et al: Impaired plasma phospholipids and relative amounts of essential polyunsaturated fatty acids in autistic patients from Saudi Arabia. Lipids in Health and Disease 2011 10:63.

Submit your next manuscript to BioMed Central and take full advantage of:

- Convenient online submission

- Thorough peer review

- No space constraints or color figure charges

- Immediate publication on acceptance

- Inclusion in PubMed, CAS, Scopus and Google Scholar

- Research which is freely available for redistribution

Submit your manuscript at www.biomedcentral.com/submit
Ciomed Central 